\title{
KANT E A HERMENÊUTICA MODERNA ${ }^{1}$
}

\author{
Joãosinho Beckenkamp ${ }^{2}$ \\ jobeck@ufpel.tche.br
}

RESUMO Encontra-se espalhada pela obra de Kant uma série de teses que dizem respeito ao que hoje é conhecido por hermenêutica, isto é, a arte ou a técnica da interpretação. Apesar da clara e marcante influência dessas teses sobre Fr. Schlegel e Schleiermacher, que devem ser reconhecidos como os verdadeiros fundadores da hermenêutica moderna, elas não são devidamente levadas em consideração pelos historiadores da hermenêutica. O presente trabalho visa recuperar a memória histórica destas conexões, no intuito de chegar a uma imagem mais justa do desenvolvimento da hermenêutica moderna.

Palavras-Chave Criticismo, Hermenêutica, Kant, Dilthey, Heidegger

\footnotetext{
ABSTRACT There are throughout Kant's work many propositions concerning to what is today called hermeneutics, i. e., the art or the technique of interpretation. Notwithstanding the clear influence of these propositions on Fr. Schlegel and Schleiermacher, who should be recognized as the founders of modern hermeneutics, they aren't duly taken in account by the historians of

1 O presente trabalho foi apresentado por partes em dois eventos consecutivos, a saber, as seções 2 e 3 no IV Congresso Kant Internacional, Porto Alegre (RS), maio de 2008, e a primeira seção no XIII Encontro Nacional de Pós-Graduação em Filosofia da ANPOF, Canela (RS), outubro de 2008.

2 Professor do Departamento de Filosofia da Universidade Federal de Pelotas (RS). Artigo recebido em $11 / 02 / 2009$ e aprovado em 10/04/2010.
}

KRITERION, Belo Horizonte, nº 121, Jun./2010, p. 275-292. 
hermeneutics. The present paper proposes to recover the historical memory of these connections, in order to attain a fair picture of the development of modern hermeneutics.

Keywords Criticism, Hermeneutics, Kant, Dilthey, Heidegger

A mesma interlocução permanente com a obra kantiana que tem permitido ao longo do tempo a explicitação do sentido e da relevância de tantas teses kantianas teve como resultado também o encobrimento de outras tantas, cujo destino parece ser o esquecimento histórico. É o caso, por exemplo, das teses propriamente hermenêuticas de Kant, que têm sido sistematicamente ignoradas por aquela linha de desenvolvimento que culminou na elevação da hermenêutica a procedimento metodológico fundamental do pensamento filosófico e, por conseguinte, do pensamento em geral.

O presente trabalho visa contribuir para a recuperação da memória do papel que as teses hermenêuticas de Kant desempenharam na constituição da hermenêutica moderna, partindo para tanto, do seu esquecimento generalizado nos trabalhos dos representantes mais significativos dessa hermenêutica, apresentando, em seguida, os traços essenciais das teses hermenêuticas de Kant e de sua aplicação na interpretação de textos bíblicos, para concluir com a indicação, em linhas gerais, do lugar que deve ser atribuído a Kant na história da hermenêutica moderna.

\section{A difícil recepção das teses hermenêuticas de Kant no contexto da hermenêutica moderna}

A ideia de uma hermenêutica universal, portanto, capaz de abranger metodologicamente o conjunto dos problemas relevantes do pensamento filosófico, foi lançada pelos primeiros românticos alemães, particularmente por Friedrich Schlegel, de quem é largamente tributário Friedrich Schleiermacher, considerado em geral o fundador da hermenêutica moderna. Ora, o programa filosófico dos primeiros românticos alemães situa-se precisamente no contexto das tentativas de superação da filosofia crítica kantiana, superabundantes na última década do século XVIII. Em sua origem, portanto, o programa de uma hermenêutica universal, que se desenvolveria no século XX a partir da proposta de uma "hermenêutica da facticidade" na obra de Heidegger, remonta 
a um momento histórico em que começa a resistência ao pensamento crítico kantiano, podendo-se considerar o método hermenêutico universalizado como um substituto do método crítico universalmente empregado por Kant.

Tendo sua origem no afã de suplantar a filosofia kantiana, a hermenêutica moderna sempre se pôs em cena como tendo definitivamente deixado para trás o pensamento kantiano, o que teve como consequência o quase total esquecimento das teses hermenêuticas espalhadas pelas obras de Kant. Tanto isso é verdade que o resgate de uma possível hermenêutica em perspectiva crítica, a ser feito aqui em seguida, acaba tendo algo de arqueológico. Trata-se de mostrar que Kant lançou os fundamentos também de uma hermenêutica futura que pudesse ser sustentada nos limites de uma filosofia crítica, e que hoje nos aparece como mais um destes projetos de futuro agora passados de que está cheio o século XVIII.

Como tese geral, entretanto, a importância de Kant para o desenvolvimento da hermenêutica moderna foi reconhecida por alguns de seus representantes mais clássicos, como Dilthey, Heidegger e Gadamer. Dilthey foi o primeiro a registrar a presença da filosofia kantiana no espaço de fundação da hermenêutica moderna. Em sua biografia de Schleiermacher, de 1860, Dilthey recapitula os estágios que levam de Kant a Schleiermacher, enfatizando a importância de alguns aspectos do texto $A$ religião nos limites da simples razão para os desenvolvimentos subsequentes. Para ele, o escrito de Kant sobre a religião é um marco na história da exegese bíblica e, por conseguinte, da hermenêutica: "Este escrito de Kant constitui uma virada decisiva da compreensão da Sagrada Escritura. O fato, o dogma, o artigo de fé não são nada como tais; eles apenas são algo na medida em que aparece neles a idéia moral-religiosa. Levando-se rigorosamente a sério este princípio, também o conteúdo da Bíblia só pode ter seu valor nesta relação. A tarefa do doutrinário da religião é, portanto, relacionar cada passagem àquela idéia; ela tem de ganhar essa relação. Ao ganhá-la, entretanto, na medida em que o mais poderoso espírito desde Leibniz luta com o cabedal de idéias da Escritura, levanta-se aqui pela primeira vez desde a Reforma uma intuição básica da Escritura, a teologia bíblica do idealismo, com base na contraposição do mal radical e da santidade da lei moral." "3 Como relevante para o desenvolvimento da hermenêutica, entretanto, Dilthey considera, não tanto a proposta kantiana de uma interpretação moral das narrativas bíblicas, portanto o conteúdo da inovação introduzida pela filosofia crítica, mas antes a simples renovação formal da ideia de uma 
interpretação unitária dos textos bíblicos: "Pela primeira vez, volta-se $a$ interpretar o todo da Escritura a partir de um único espírito que permeia o todo. Esta orientação da exegese, entretanto, no sentido de compreender a Escritura como um todo orgânico que cresce de uma substância unitária se coloca como segunda e igualmente digna orientação ao lado daquela voltada para o tratamento filológico dos textos singulares. E como renovador desta orientação, não como o autor daquela infeliz assim chamada 'interpretação moral', Kant ocupa uma posição que fez época na história da hermenêutica." 4 Em sua biografia de Schleiermacher, então, Dilthey expõe o desenvolvimento consequente desta ideia de uma interpretação unitária na hermenêutica schleiermacheriana, deixando patente a importância da filosofia kantiana para a constituição de uma hermenêutica moderna. ${ }^{5}$

Apesar de em sua biografia de Schleiermacher ter registrado a posição de Kant no desenvolvimento da hermenêutica moderna, Dilthey acabou posteriormente enquadrando a filosofia crítica kantiana num esquema que mostra a influência do neokantismo: o essencial da contribuição de Kant é sua crítica da razão pura, cujo núcleo duro seria a crítica ou a teoria do conhecimento das ciências naturais. Recapitulando o desenvolvimento da hermenêutica moderna, Gadamer apontava para esta limitação da leitura que Dilthey faz de Kant em sua obra madura: "A ambição de Dilthey de colocar a crítica da razão histórica ao lado da crítica kantiana e a teoria neokantiana de Windelband e Rickert de um conhecimento histórico sob a idéia sistemática de um reino dos valores testemunham à sua maneira a supremacia da crítica kantiana. Mas estão longe de corresponder à autocompreensão de Kant segundo a qual ele teria indicado os limites do saber para ganhar lugar para a fé.” Enquadrando Kant no cenário da disputa entre ciências naturais e históricas do lado dos pensadores dos fundamentos da ciência natural, Dilthey desperdiça a oportunidade de situá-lo no contexto mais amplo do desenvolvimento da nova hermenêutica. O dito kantiano de que foi necessário determinar os limites do conhecimento para deixar um lugar para a fé diz respeito precisamente à

DILTHEY, W. Gesammelte Schriften XIV/2 (Leben Schleiermacher, Bd. 2), p. 652.

$5 \mathrm{Na}$ pesquisa mais recente do contexto de constituição da hermenêutica moderna em torno de Schleiermacher, estabeleceu-se finalmente a importância de Fr. Schlegel como elo intermediário entre Kant e Schleiermacher, podendo-se mesmo mostrar que as teses mais fundamentais da hermenêutica schleiermacheriana remontam a elaborações de Schlegel, tendo sido transmitidas nos anos de sua amizade em Berlim no fim do séc. XVIII. Reservo para uma outra ocasião a reconstituição dos desenvolvimentos que levam das teses embrionárias de Kant, por intermédio de Fichte e sobretudo de Fr. Schlegel, até Schleiermacher, do qual se disse com razão que "vale como o pai da hermenêutica moderma e do movimento hermenêutico" (MUBNER, Franz. Geschichte der Hermeneutik: Von Schleiermacher bis zur Gegenwart, Freiburg/Basel/Wien, Herder, 1976, p. 4.).

6 GADAMER, H.-G. Kant und die philosophische Hermeneutik. Kant-Studien, 66, p. 396, 1975. 
intenção sistemática mais abrangente de Kant, cuja envergadura não se deixa visualizar na Crítica da razão pura, mas que se mostra decisiva nas obras posteriores voltadas para a filosofia prática e a estética. É neste contexto mais amplo, geralmente ignorado pelo neokantismo do séc. XIX, que se encontram as bases daquela proposta de interpretação de textos bíblicos em termos da moralidade, cuja intenção unitária foi devidamente identificada como um marco histórico do desenvolvimento da hermenêutica pelo jovem Dilthey.

Ainda em sua última obra, A construção do mundo histórico nas ciências do espírito, de 1910, Dilthey situa a realização de Kant sobretudo na análise dos fundamentos da ciência da natureza, apesar de registrar en passant também a importância da filosofia kantiana para o desenvolvimento da consciência histórica: "A nova teoria da história teve naturalmente seu duplo ponto de partida no idealismo filosófico alemão e na revolução da ciência histórica. Comecemos pelo primeiro. Tinha sido o problema de Kant saber como se poderia encontrar no transcurso histórico um encadeamento unitário, "uma marcha regular". Ele não pergunta, à maneira da teoria do conhecimento, pelas condições do encadeamento existente na ciência dada, mas sua pergunta vai no sentido de saber como se poderia derivar a priori da lei moral, a que está submetido todo agir, princípios para a concepção do material histórico. ${ }^{7}$ Dilthey reconhece assim, não só a importância da filosofia da história de Kant para o desenvolvimento da subsequente teoria da história, mas inclusive o princípio que norteia uma investigação kantiana naqueles âmbitos que não se deixam reduzir à ciência físico-matemática, a saber, o princípio da moralidade. Com isto, entretanto, é reconhecido que Kant inaugura na verdade um desenvolvimento ainda em curso na época de Dilthey: “A importância de Kant neste domínio consiste, portanto, inicialmente em ter aplicado o ponto de vista da filosofia transcendental à história, inaugurando assim uma concepção duradoura da história cuja essência consiste no estabelecimento de um critério absoluto fundamentado na essência da própria razão, de um incondicionado como valor ou norma." ${ }^{8}$ Para precisar o lugar de Kant no desenvolvimento da consciência histórica, esse reconhecimento da importância da exigência kantiana de um tratamento unitário do material sob o critério da lei moral deveria ter fornecido o fio condutor da investigação de Dilthey. Em vez disto, no entanto, Dilthey se atém no resto do texto à sua correlação entre ciências naturais, para as quais Kant teria estabelecido os princípios a priori, e

7 DILTHEY, W. Der Aufbau der geschichtlichen Welt in den Geisteswissenschaften. Frankfurt a.M.: Suhrkamp, 1981. p. 126.

8 DILTHEY, W. Der Aufbau der geschichtlichen Welt in den Geisteswissenschaften, p. 127. 
ciências históricas, nas quais a revolução deveria vir de Dilthey: "Kant partiu dos fundamentos que se encontram na lógica formal e na matemática para o tratamento do problema do conhecimento. [...] A grandeza de sua realização consistiu numa análise completa do conhecimento matemático e das ciências naturais. Mas a questão é se uma teoria do conhecimento da história, que ele próprio não forneceu, é possível nos moldes de seus conceitos." "A resposta de Dilthey a essa última questão naturalmente continua negativa, o que desloca, contudo, o lugar adequado para a investigação. Pois a questão não deveria ser se é possível uma teoria do conhecimento histórico nos moldes da filosofia crítica kantiana, mas em que medida a exigência de um tratamento unitário do material histórico formulada por Kant influenciou o desenvolvimento da filosofia e, por fim, da teoria da história.

Como lembrava ainda Gadamer, a redescoberta de uma intenção mais profunda ou mais abrangente da filosofia kantiana veio com o programa heideggeriano de uma hermenêutica da facticidade, que, dando novo alento à tradição hermenêutica, acabaria surpreendentemente resgatando um Kant até então ignorado: "Entretanto a intenção própria de Heidegger, que acompanhava sua retomada da problemática hermenêutica das ciências teológicas e históricas, haveria de se impor rapidamente e, assim, despertar de maneira surpreendente para uma nova atualidade o Kant originário contra seus sucessores especulativos." ${ }^{10}$ O que a recepção de Kant por seus sucessores e pelo neokantismo ajudou a encobrir se encontra no cerne da filosofia transcendental kantiana, a saber, a necessária referência do entendimento ou da razão à intuição no caso de pretender chegar ao conhecimento de seu objeto. Essa necessária referência constitui já em Kant o fator principal de uma limitação de toda pretensão cognitiva ao âmbito da experiência. Heidegger retoma esta tese kantiana no intuito de reforçar sua filosofia da finitude, que encontra na hermenêutica da facticidade seu arcabouço metodológico apropriado. Pode, assim, avançar decisivamente além daquilo que se pretendia saber de Kant até o neokantismo: "No caminho de seu aprofundamento ontológico do programa da filosofia da vida e em meio a toda a crítica da filosofia da consciência da modernidade, Heidegger descobre então repentinamente Kant. E, na verdade, justamente aquilo em Kant que o neokantismo e seu acabamento fenomenológico tinham encoberto: a dependência do dado. Justamente porque a existência humana não é um autoprojeto livre, uma auto-realização do espírito, mas ser para a morte, e isso significa essencialmente finita, 
Heidegger pode reconhecer na doutrina kantiana da inter-relação de intuição e entendimento e da limitação um prenúncio de suas próprias idéias." 11

A leitura inicial que Heidegger faz de Kant, em particular da Crítica da razão pura, é marcada precisamente por este propósito de mostrar, contra o neokantismo oitocentista, que a filosofia transcendental confere um certo primado ao elemento intuitivo. A tendência fundamental da leitura neokantista de Marburgo, que constitui o alvo principal da crítica de Heidegger, é a redução da intuição ao pensamento puro, tendência muito forte particularmente em Cohen e Natorp. Heidegger entra na discussão defendendo precisamente o contrário: “o segundo elemento, o pensamento puro, ocupa em relação à intuição essencialmente uma posição de serviço. Ao pensamento puro pertence, pois, essencialmente, e não acidentalmente e por acréscimo, a dependência em relação à intuição pura." ${ }^{2}$ Marcando na crítica kantiana o momento da essencial finitude das pretensões cognitivas de todo o nosso pensamento, a tese da necessária referência do pensamento à intuição na constituição do conhecimento objetivo é resgatada por Heidegger como princípio de sua interpretação do projeto kantiano tanto em Kant e o problema da metafísica, publicado em 1929, quanto em A interpretação fenomenológica da Crítica da razão pura de Kant, lições publicadas apenas postumamente, em 1977, mas proferidas no semestre de inverno entre 1927 e $1928 .{ }^{13}$ Em ambas as exposições, Heidegger acompanha Kant até o capítulo do esquematismo transcendental, para mostrar até que ponto a filosofia transcendental chegou à consciência da essencial temporalidade de nosso conhecimento ao expor os esquemas da imaginação transcendental ou da intuição pura.

O resgate da tese capital da filosofia transcendental kantiana, a saber, da necessária inter-relação entre entendimento e intuição, como prenúncio da nova hermenêutica da facticidade constitui certamente um capítulo importante na ampliação da compreensão da filosofia kantiana como um todo, mas não leva a suplantar o encobrimento da relação histórica original entre a crítica kantiana e a hermenêutica moderna, pois não chega sequer a descortinar o horizonte prático em que se situam as teses propriamente hermenêuticas

11 GADAMER, H.-G. Kant und die philosophische Hermeneutik, p. 401.

12 HEIDEGGER, M. Kant und das Problem der Metaphysik. Frankfurt a. M.: V. Klostermann, 1951. p. 57.

$13 \mathrm{Na}$ altura em que Heidegger profere estas lições, sua concepção da fenomenologia já superou aquela desenvolvida por Husserl e sua escola, tendo em Ser e tempo redefinido os conceitos de fenômeno e fenomenologia e indicado como sentido metodológico da descrição fenomenológica a interpretação, com o que a própria fenomenologia aparece como hermenêutica: "Fenomenologia do ser-aí é hermenêutica no sentido original da palavra em que designa o ofício da interpretação" (HEIDEGGER, M. Sein und Zeit. Tübingen: Niemeyer, 1986. p. 37). A interpretação fenomenológica do projeto crítico kantiano proposta por Heidegger constitui, portanto, propriamente o prospecto de uma interpretação hermenêutica da Crítica da razão pura. 
de Kant. Tal como ocorre em Dilthey, também Heidegger retoma o projeto da crítica kantiana no domínio teórico, superando sem dúvida a estreiteza da interpretação neokantista, mas sem abandonar a limitação da análise a um âmbito que não permite ainda situar o que Kant dizia a propósito da interpretação. A filosofia transcendental kantiana pode aparecer, assim, como precursora em certa medida daquilo que Heidegger pretende realizar em termos de conteúdo, a saber, recuperar a questão central de uma ontologia fundamental acerca do ser do ente, ficando inteiramente esquecido o lugar que as teses hermenêuticas de Kant ocupam na história daquele desenvolvimento da consciência do problema metodológico colocado pelo saber histórico, no fim do qual a hermenêutica pode adquirir o status de procedimento metodológico fundamental. ${ }^{14}$ A contribuição da crítica kantiana na constituição de uma hermenêutica moderna que culminaria no projeto heideggeriano de uma hermenêutica da facticidade permanece, assim, inteiramente encoberta e esquecida.

Representantes tardios da nova hermenêutica, como Gadamer e Ricoeur, apenas repetem, no concernente ao tópico aqui abordado, a linha de leitura introduzida por Dilthey e Heidegger, podendo ser constatado que na historiografia da hermenêutica moderna os textos em que Kant apresenta suas teses propriamente hermenêuticas e mostra como podem ser aplicadas são ignorados, voltando-se sempre à ideia diltheiana de que Kant realizou uma revolução na compreensão das ciências naturais que deve ser complementada por uma revolução semelhante na compreensão das ciências históricas e do espírito, para a qual, entretanto, Kant não teria contribuído em nada.

$\mathrm{O}$ resgate das teses hermenêuticas de Kant e sua colocação no contexto constitutivo da nova hermenêutica levam, contudo, à conclusão oposta, tratando-se em seguida de apontar para este cenário em que se descortina uma outra versão da história da hermenêutica moderna.

14 Cf. Sein und Zeit, § 7, item C. A preservação do jargão fenomenológico na primeira fase da obra de Heidegger dificulta a percepção de que ele constitui o ponto culminante do desenvolvimento da hermenêutica moderna. Já em Ser e tempo a hermenêutica é anunciada como o procedimento metodológico característico da filosofia: "Ontologia e fenomenologia não são duas disciplinas distintas pertencentes à filosofia ao lado de outras. Os dois títulos caracterizam a própria filosofia segundo o objeto e o procedimento. Filosofia é ontologia fenomenológica universal partindo da hermenêutica do ser-aí, que como analítica da existência fixou o fim do fio condutor de toda interrogação filosófica lá onde ela se origina e para onde retorna." (Sein und Zeit, p. 38). 


\section{Interpretação < Auslegung, Deutung > em Kant}

Como já apresentei em outro lugar o essencial da hermenêutica crítica kantiana, ${ }^{15}$ limito-me neste tópico a retomar o que foi dito lá a propósito da interpretação propriamente dita. As formulações mais gerais de Kant sobre interpretação, exegese e hermenêutica são encontradas em seu opúsculo $O$ conflito das faculdades, publicado em 1798. Tratando de delimitar as competências respectivas da faculdade de Filosofia e das faculdades superiores de Teologia, Direito e Medicina, Kant explicita em relação à Teologia o que constitui a contribuição específica da Filosofia para a interpretação de textos religiosos, defendendo o procedimento que adotara em seu texto de 1793 sobre A religião nos limites da simples razão. Diante da tradição teológica, trata-se, portanto, para o filósofo, de estabelecer "princípios filosóficos da interpretação da Escritura" (AA VII, 38), ${ }^{16}$ formulando-se a "regra suprema da interpretação <Interpretation>" (AA VII, 41) nos seguintes termos: "Passagens que contêm certas doutrinas teóricas, anunciadas como sagradas, mas que ultrapassam todo conceito racional (até mesmo o prático) podem, aquelas passagens, entretanto, que contêm proposições que contradizem à razão prática devem ser interpretadas em favor da última" (Der Streit der Fakultäten, AA VII, 38). Essa regra formula a pretensão da razão a se constituir como autoridade suprema também no âmbito da interpretação de textos religiosos, desdobrando-se em duas partes. Com a primeira parte da regra, concernente àquelas narrativas cujo sentido literal ultrapassa os limites da razão sem, no entanto, entrar em contradição com os princípios racionais, torna-se disponível para a interpretação racional o conjunto dos textos sagrados, seja aqueles que já se atêm ao "conceito racional", seja aqueles que o ultrapassam, exigindo assim uma interpretação racional. Com a parte final da regra, concernente àquelas narrativas que entram em contradição com a razão, é mesmo formulado um princípio de intervenção no âmbito das interpretações religiosas, devendo ser combatido o desdobramento irracional e sugerida uma interpretação racional dessas narrativas.

Apesar do enorme desafio que um tal princípio racional de interpretação constitui para uma teologia tradicional e dogmática, Kant acredita poder contar com o apoio de uma faculdade teológica esclarecida, pois mesmo os

15 Ver A interpretação de narrativas religiosas e sua relação com a semântica de conceitos da razão prática pura. In: COLÓQUIO KANT: PROBLEMAS SEMÂNTICOS NA DOUTRINA KANTIANA DA RELIGIÃO, 8., 2006, Campinas. Trabalho apresentado. Campinas: UNICAMP, 2006, e publicado em Kant e-prints, Campinas, v. 2, n. 2.

16 Citações de textos de Kant são referidas como de praxe pela edição da Academia, abreviada para AA, seguido de volume em número romano e página em número arábico. 
teólogos concederiam, ao distinguir entre expressão humana e sentido divino, que "a razão é, em matérias religiosas, a intérprete $<$ Auslegerin $>$ suprema da Escritura" (AA VII, 41). Esta expectativa de Kant só se justifica diante do desenvolvimento que a teologia protestante sofreu desde a Reforma até a Época das Luzes, dando margem à esperança de que um dia a própria teologia se harmonizaria plenamente com a razão. No contexto da proibição de se manifestar sobre assuntos religiosos, sofrida por Kant em 1794, trata-se aqui, não de uma ingenuidade, mas de uma expectativa motivada pela própria razão.

Em termos de técnica interpretativa, a regra mencionada pressupõe a distinção entre o sentido literal de uma narrativa e o sentido que se estabelece pela interpretação. ${ }^{17}$ Assim, as narrativas bíblicas podem ser "tomadas como verdadeiras literalmente $<$ buchstäblich für wahr gehalten $>$ " ou "interpretadas de certa maneira <doch so ausgelegt>" (Der Streit der Fakultäten, AA VII, 41). Ao "sentido literal <der buchstäbliche Sinn>" (AA VII, 41) podem ser contrapostos sentidos estabelecidos por interpretação, por exemplo, mediante "a idéia de uma interpretação filosófica da Escritura" (AA VII, 44). Assim, a interpretação que Kant sugeriu em A religião nos limites da simples razão é uma aplicação dessa ideia de uma interpretação filosófica da Escritura, tendo como fio condutor o princípio da moralidade. O sentido literal é designado também "a letra", contrapondo-se-lhe "o espírito" (Cf. AA VII, 64), que na interpretação kantiana é o sentido moral. A crença no sentido literal ou na mera letra da narrativa "é morta em si mesma" (AA VII, 66), enquanto só o espírito ou a crença no sentido moral vivifica e torna bem-aventurado (Cf. AA VII, 67).

Abrindo os textos bíblicos para o campo das interpretações, a regra da interpretabilidade dos textos e discursos religiosos leva naturalmente ao desenvolvimento de uma técnica da interpretação, a fim de suplantar a total arbitrariedade que se estabeleceria com interpretações sem nenhum critério. Esta técnica é a hermenêutica, cujo desenvolvimento inicial se dá como "arteltécnica da interpretação <Auslegungskunst> bíblica (hermenêutica sacra)" (AA VII, 66). A hermenêutica pode tomar o texto sagrado como autêntico, quer dizer, como expressando a intenção do autor, caso em que "a interpretação tem de ser adequada literalmente (filologicamente) ao sentido do autor" (AA VII, 66), ou então em sentido doutrinal, quando o intérprete "tem a liberdade de atribuir à passagem (filosoficamente) aquele sentido que ela adquire na exegese em perspectiva prático-moral” (AA VII, 66). interpretação, no caso fornecida pela própria linguagem. 
Ora, tão somente a interpretação doutrinal adota como critério o progresso moral dos povos, enquanto a interpretação literal se aferra ao sentido literal das narrativas, menosprezando mesmo a possibilidade de que seus autores tenham se equivocado ou representem um estágio pouco desenvolvido do conhecimento e da moralidade: "Portanto o único método bíblico-evangélico de instruir o povo na verdadeira religião interior e universal é tão-somente aquela interpretação doutrinal que não exige conhecer (empiricamente) qual sentido o autor sagrado pode ter dado a suas palavras, mas qual doutrina a razão pode ocasionalmente atribuir (a priori) a um trecho da Bíblia em perspectiva prática" (Der Streit der Fakultäten, AA VII, 67).

$O$ conflito das faculdades explicita, assim, os princípios filosóficos da interpretação de narrativas religiosas, fornecendo finalmente o fundamento da interpretação filosófica de algumas dessas narrativas apresentada por Kant em $A$ religião nos limites da simples razão. Essa obra visa uma interpretação unitária das narrativas bíblicas sob o princípio único da moralidade. A filosofia moral kantiana abriu também espaço para uma religião racional ou uma fé moral, na perspectiva da complementação das exigências rigorosas da razão prática pura num ser limitado e mesclado com elementos sensíveis como é o ser humano. A Crítica da razão prática reconhece a necessidade de um ser racional finito acreditar na existência de Deus, introduzindo-a como um postulado da razão prática e autorizando, assim, a crença religiosa e o cultivo de uma religião racional em perspectiva moral. Ora, historicamente seres racionais finitos como os homens sempre já se deparam com crenças empiricamente constituídas, nas quais os povos satisfazem aquela "necessidade natural de todos os homens de obter para os supremos conceitos e fundamentos racionais sempre algo sensivelmente seguro, uma confirmação qualquer da experiência etc." (Die Religion, AA VI, 110). Historicamente, portanto, a autorização do cultivo da religião racional visando a complementação sensível das exigências da razão leva à necessidade de harmonizar aquelas crenças empíricas com o fundamento da fé moral, tornando indispensável a hermenêutica, pois "para tanto é exigida uma interpretação $<$ Auslegung $>$ da revelação que chegou até nós, i. é, uma completa interpretação $<$ Deutung $>$ da mesma em um sentido que concorda com as regras práticas universais de uma religião racional" (Die Religion, AA VI, 110). Está respondida assim a questão que Kant formula em nota: "pergunto se a moral deve ser interpretada segundo a Bíblia ou antes a Bíblia deve ser interpretada segundo a moral" (Die Religion, AA VI, 110 nota). Sendo o fim de toda atividade racional a promoção da moralidade, a complementação sensível que a razão prática pura encontra nas narrativas bíblicas só será autorizada segundo o princípio da própria moralidade: "Uma 
vez que o aprimoramento moral do homem constitui propriamente o fim de toda religião racional, essa conterá também o princípio supremo de toda interpretação da Escritura" (Die Religion, AA VI, 112).

O princípio da moralidade constitui, portanto, o critério de uma interpretação unitária das narrativas bíblicas com a qual Kant marca presença na história da exegese bíblica e da hermenêutica em geral. Pois este procedimento interpretativo com base em um critério único suplanta a arbitrarieridade e a aleatoriedade que o princípio da interpretabilidade das narrativas traz consigo. A hermenêutica kantiana opera segundo um princípio que lhe permite determinar de maneira unificada "o sentido que damos aos símbolos da fé popular ou também dos livros sagrados" (Die Religion, AA VI, 111). Os símbolos da crença popular são produtos da fantasia ou imaginação dos povos, tendo em geral um sentido literal na própria representação popular. $\mathrm{Na}$ medida em que "a religião racional pura tem de ser a intérprete" (Die Religion, AA VI, 160) desses símbolos para que sejam adequados à simbolização dos conceitos da razão prática pura, ela não pode se ater ao sentido literal que a crença popular geralmente lhes confere, mas também não pode simplesmente ignorar a representação dos povos, tratando-se de lhe "atribuir um sentido espiritual [...] sem entrar em conflito com o sentido literal da fé popular" (Die Religion, AA VI, 111).

As narrativas religiosas, os símbolos da crença popular, constituem em geral "artigos de fé $<$ Glaubensmeinungen $>$ [...] nas quais não se consegue alcançar de forma alguma qualquer concordância se não se apela para a razão pura como intérprete" (Die Religion, AA VI, 130). Ao longo do texto sobre a religião, quando a razão pura opera como intérprete, encontra-se explicitado este procedimento interpretativo em formulações como "dar-lhe a última interpretação" (AA VI, 113) ou "isto pode certamente ser interpretado assim" (AA VI, 121 nota) ou ainda: "pode-se interpretá-lo como uma representação puramente simbólica" (AA VI, 134). Em todos estes casos, a interpretação consiste em conferir um sentido moral ou puramente racional àqueles produtos da fantasia popular que constituem as narrativas religiosas.

\section{O lugar de Kant na história da hermenêutica moderna}

Desde os pioneiros trabalhos de Dilthey sobre Schleiermacher, reconhecese a importância de Kant na constituição da hermenêutica moderna, mas não se lhe confere o lugar devido em sua história. Como apontou Dilthey, o propósito kantiano de interpretar segundo um princípio único os textos sagrados descortinou o horizonte daquilo que viria a constituir a nova hermenêutica, 
chamando a atenção em pleno final de Século XVIII para a importância e as potencialidades contidas em narrativas religiosas e mitológicas. O que na perspectiva do esclarecimento setecentista tendia a ser reduzido a um material histórico morto e improfícuo, quando não pernicioso, volta a ganhar relevância e a constituir ponto de partida de uma elaboração viva do espírito, desde que submetido ao princípio da interpretabilidade que animará a nova hermenêutica. Viu-se na seção anterior com que empenho e coerência Kant defendeu esse princípio.

Situando-se o ato fundador da hermenêutica moderna no primeiro romantismo alemão, com referência particularmente em Fr. Schlegel e Schleiermacher, pode-se mostrar, entretanto, que a influência de Kant neste contexto vai além de uma mera inspiração longínqua, como sugere o enquadramento proposto por Dilthey. $\mathrm{Na}$ verdade, teses kantianas fundamentais neste âmbito entraram para o cabedal definitivo da hermenêtica através de Schlegel e Schleiermacher, ambos leitores assíduos de Kant na época em que firmaram os princípios de sua hermenêutica (1797-1799). Uma lista completa dessas teses incorporadas ainda está por ser estabelecida, mas duas delas adquiriram tal proeminência, que é difícil ignorar sua presença nos textos de Kant. Trata-se da tese de que a tradição exegética pode basearse num mal-entendido, portanto, da tese da possibilidade do erro, e da tese de que é possível entender um autor melhor do que ele próprio se entendia. Nos textos de Schlegel e Schleiermacher sobre hermenêutica, as duas teses são desenvolvidas nas mais variadas formulações, tratando-se aqui de mostrar sua origem no texto kantiano.

Antes disto, entretanto, será interessante ainda apontar para um terceiro tema caro à hermenêutica e que encontra em Kant igualmente algumas indicações relevantes. Trata-se neste caso da relação entre o princípio da interpretação e a filologia. Apesar de Kant sugerir em várias passagens que o aspecto histórico das narrativas interpretadas é indiferente para a interpretação racional, encontram-se também trechos que reconhecem a importância do conhecimento do sentido literal dos textos interpretados. Na perspectiva do princípio da interpretabilidade, ou seja, para a simples interpretação moral dos textos sagrados, não é necessário mostrar que seus autores tenham tido essa intenção, mas é suficiente "admitir tão-somente a possibilidade de entender desta maneira os autores dos mesmos" (Die Religion, AA VI, 111). Pois o objetivo da leitura e da interpretação destes textos deve ser sempre tornar os homens melhores, sendo de menor importância os detalhes históricos: "a leitura destes textos sagrados ou a investigação de seu conteúdo tem por intenção última fazer homens melhores; mas o histórico que não contribui para 
tanto é algo em si totalmente indiferente, que se pode tomar como se quiser" (Die Religion, AA VI, 111). Apesar de o princípio da interpretabilidade dos textos sagrados constituir, assim, o princípio supremo da leitura e do estudo destes textos, parecendo dispensar completamente a informação histórica e filológica, Kant admite a importância também da crítica histórica e da filologia para a interpretação dos textos, incluindo o conhecimento das respectivas línguas: "Pois como o inculto que só os pode ler em traduções quer ter certeza do sentido dos mesmos? Por isto, o intérprete, que também domina a língua original, tem de possuir ainda vasto conhecimento histórico e crítica para retirar do estado, dos costumes e das opiniões (da fé popular) daquele tempo os meios com os quais pode ser aberto o entendimento da comunidade" (Die Religion, AA VI, 112). Ao intérprete racional, portanto, "junta-se ainda um outro, mas subordinado, a saber, o filólogo $<$ Schriftgelehrte $>$ " (Die Religion, AA VI, 112), cabendo a ambos a tarefa de cuidar dos textos sagrados: "Religião racional e filologia <Schriftgelehrsamkeit $>$ são, portanto, os verdadeiros intérpretes e depositários de um documento sagrado" (Die Religion, AA VI, 113).

$\mathrm{Na}$ Antropologia, concede-se mesmo a necessidade de interpretar literalmente os autores quando se trata de investigar a intenção que possam ter tido na redação de seus textos. O princípio da interpretação racional não é comprometido com isso, tratando-se sempre de alcançar o sentido racional e moral que os textos comportam: "Constitui esclarecimento distinguir, na apresentação dos conceitos pertencentes à moralidade que perfaz a essência de toda religião, portanto dos conceitos pertencentes à razão pura (chamados idéias), o simbólico do intelectual (culto divino de religião), a roupagem, por algum tempo útil e necessária, da própria coisa; pois do contrário um ideal (da razão prática pura) seria trocado por um ídolo, frustrando-se o fim último. - Não há dúvida de que todos os povos da Terra começaram com essa troca e que, tratando-se daquilo que seus doutrinadores realmente pensaram na redação de seus textos sagrados, não se deve interpretá-los simbolicamente, mas literalmente, pois seria desonesto torcer suas palavras. Tratandose, no entanto, não apenas da veracidade do doutrinador, mas também e essencialmente da verdade da doutrina, pode-se e deve-se interpretá-los como modo de representação meramente simbólico [...]; pois do contrário seria perdido o sentido intelectual que constitui o fim último" (Anthrop. § 39, AA VI, 192). Para o desenvolvimento subsequente da hermenêutica, tanto a dimensão da veracidade dos autores quanto a da verdade de seus textos, a filologia e a interpretação racional, constituem partes indispensáveis de um mesmo projeto hermenêutico, aprofundando-se ao mesmo tempo a investigação filológica, que 
acarreta o desenvolvimento da crítica histórica e filológica, e a interpretação em vista de uma unidade superior.

Voltando-nos, finalmente, para aquelas teses repercutidas incessantemente pela hermenêutica moderna, vemos Kant insistir na possibilidade de um mal-entendido na interpretação tradicional dos textos sagrados, o que retira o fundamento da certeza numa fé baseada meramente na tradição histórica. Por mais que o crente viva na convicção de que os dogmas de sua crença são oriundos de uma revelação divina, ele não pode ter certeza disso, pois seu conhecimento a respeito se baseia numa cadeia histórica: "A revelação chegou até ele tão-somente através de homens e por eles interpretada [...] sendo ao menos possível que se imponha aqui um erro" (Die Religion, AA VI, 187). Assim, toda fé baseada meramente na tradição e no legado histórico está exposta ao princípio da incerteza que decorre do fato de "que sempre resta a possibilidade de que se encontre nisso um erro" (Die Religion, AA VI, 187). Enquanto a convicção do crente não tem outro fundamento a não ser as demonstrações históricas, não pode ser obrigado nem deve querer obrigar os outros a admitir dogmas cujo único fundamento é a tradição histórica, pois isso implicaria uma limitação do juízo imposta num caso em que não há razão suficiente para a certeza, visto que "sempre resta a absoluta possibilidade de um erro cometido em sua interpretação clássica" (Die Religion, AA VI, 187). Ora, um erro de interpretação constitui bem um mal-entendido (Missveständnis) e interpretar um texto erroneamente é simplesmente entendê-lo mal (missvestehen). Quando Schlegel e, mais tarde, Schleiermacher partem do princípio de que é preciso primeiramente desfazer os mal-entendidos tradicionais, estão de fato reverberando uma tese kantiana no âmbito da hermenêutica.

O mesmo acontece com a paradoxal tese de que é possível entender um autor melhor do que ele próprio se entendia. Em Schlegel, por exemplo, a tese é variada e sofisticada, como no fragmento 401 da série publicada na revista Athäneum: "Para entender alguém, temos de ser, em primeiro lugar, mais esperto do que ele, em seguida, igualmente esperto, e então também igualmente burro. Não basta que se entenda o sentido próprio de uma obra confusa melhor do que o autor a entendeu. É preciso conhecer também a própria confusão até os princípios e saber caracterizá-la e mesmo construí-la." ${ }^{18}$ Nos apontamentos de Schlegel por ocasião de suas leituras de Kant nos anos 1790, encontram-se diversas formulações que operam com a possibilidade de ir além 
do próprio autor na compreensão de um texto. A inspiração kantiana dessas formulações é inequívoca e, levando em consideração o lugar proeminente que a tese ocupa na Crítica da razão pura, também compreensível. Pois Kant a introduz no momento em que passa a investigar as ideias da razão, procurando inicialmente um termo adequado para dar expressão aos conceitos próprios da razão. Ou seja, a tese é proposta num preâmbulo metodológico que diz respeito simplesmente ao sentido geral daquelas representações que constituem o alvo primordial dos desenvolvimentos filosóficos pós-kantianos tanto no romantismo quanto no idealismo alemães, a saber, os conceitos ou ideias da razão em contraposição aos meros conceitos da experiência ou do entendimento. Kant lembra neste contexto que Platão se valera da expressão 'ideia' para caracterizar, segundo a compreensão de Kant, um pensamento que ultrapassa os conceitos do entendimento a ponto de não ser possível encontrar na experiência algo que lhe corresponda. Parecendo-lhe adequada a expressão, Kant a adota para designar os conceitos puros da razão, sendo-lhe indiferente, entretanto, se foi esse o sentido que Platão de fato lhe deu. Assim como na interpretação de narrativas religiosas, Kant faz valer também em relação a textos filosóficos o princípio da interpretabilidade, chegando a sugerir que é mesmo possível entender um autor melhor do que ele próprio se entendia: "Não quero aqui me enredar numa investigação literária para estabelecer o sentido que o sublime filósofo ligou à sua expressão. Apenas observo que não é nada incomum, tanto na conversa ordinária quanto em textos, através da comparação dos pensamentos que um autor externa sobre seu objeto, entendêlo mesmo melhor do que ele próprio se entendeu, na medida em que não determinou suficientemente seu conceito e, assim, por vezes falou ou também pensou contra sua própria intenção" (KrV, A313-4/B370). Kant não aplica a Platão, entretanto, a tese introduzida neste contexto, limitando-se a registrar a proveniência platônica do termo 'ideia' que passa a empregar para designar os conceitos da razão. A elaboração e a aplicação da tese de que é possível entender um autor melhor do que ele mesmo se entendia será uma tarefa importante da geração seguinte, constituindo elementos fundamentais da nova hermenêutica.

A aplicação do princípio da interpretabilidade a textos ou discursos filosóficos é feita por Kant em outra ocasião, tratando-se da defesa de um autor contra os mal-entendidos propostos por seus intérpretes tradicionais, algo que também será prática comum na nova crítica que se estabelece com o primeiro romantismo alemão. Respondendo a ataques de Eberhard contra a crítica da razão pura, Kant defende Leibniz das distorções inconsequentes a que seu pensamento é submetido na interpretação do wolffiano Eberhard. Numa 
estratégia de defesa surpreendente, Kant se recusa a tomar a interpretação eberhardiana (e, portanto, wolffiana) do pensamento de Leibniz como adequada, uma vez que levaria a lhe atribuir uma falta de coerência que, na verdade, compromete apenas a interpretação. Na defesa da filosofia crítica contra os ataques dos leibnizo-wolffianos, Kant desloca, assim, o debate para a arena dos conflitos de interpretações, sugerindo mesmo que a crítica da razão pura permite colocar numa luz mais favorável o pensamento de Leibniz e de outros antigos, ao removê-los do contexto das interpretações banais e interpretá-los a partir da única fonte disponível na compreensão filosófica: "Assim, pois, a crítica da razão pura bem poderia ser a verdadeira apologia do próprio Leibniz, contra seus adeptos que o enaltecem com elogios nada honrosos; como ela pode, aliás, ser também para vários filósofos mais antigos, aos quais muito historiador da filosofia, apesar de todo o louvor que recebem, faz dizer disparates cuja intenção não adivinha, descuidando a chave de todas as interpretações de produtos da razão pura com base em meros conceitos, qual seja, a própria crítica da razão (como a fonte comum de todos), e deixando de ver, de tanto investigar literalmente o que aqueles disseram, aquilo que queriam dizer" (Über eine Entdeckung, AA VIII, 250-1). Anuncia-se, neste procedimento de defesa de um clássico da filosofia moderna, uma nova perspectiva no âmbito da interpretação dos textos filosóficos, uma perspectiva que será amplamente explorada pelos românticos e pelos idealistas alemães, culminando então na grande síntese de Hegel. O afã dos posteriores de se anunciarem como os arautos do novíssimo pensamento levou sempre ao esquecimento da origem próxima dos procedimentos de interpretação filosófica, que tão profícuos se mostraram para o próprio pensamento filosófico. Ao historiador da filosofia compete corrigir estas injustiças históricas.

Para concluir, pode-se dizer que a contribuição mais importante de Kant para o desenvolvimento posterior de uma hermenêutica moderna consiste em ter deslocado o alvo dos procedimentos de interpretação do tradicional estabelecimento de uma suposta verdade contida na letra dos textos (o que Kant chama sua veracidade) para a articulação do sentido que constitui aquele mesmo que interpreta. ${ }^{19}$ No texto sobre a religião, Kant explicita esta dimensão da apropriação interpretativa de narrativas religiosas citando uma bem conhecida passagem das Sátiras de Horácio: "Mutato nomine de te

$19 \mathrm{Se}$ se quisesse estender o termo 'transcendental' para além do contexto ontológico, poder-se-ia caracterizar este deslocamento como a inflexão transcendental na história da hermenêutica, semelhante àquela realizada pela revolução copernicana que deslocou o pensamento ontológico da esfera do objeto para a do sujeito transcendental. A importância desta inflexão se torna patente no movimento do primeiro romantismo, que dela parte e dá uma primeira demonstração de sua proficuidade. 
fabula narratur." ${ }^{20}$ (Die Religion, AA VI, 42). Sob os mais diversos nomes e as mais diversas roupagens, o que está em jogo na interpretação racional das narrativas é o próprio ser racional que se põe a interpretar para chegar a uma representação mais clara e intuitiva de seus conceitos puramente racionais. $\mathrm{Na}$ roupagem sensível das narrativas religiosas adquire densidade intuitiva a ideia personificada que "tem sua realidade em relação prática completamente em si mesma, pois se encontra em nossa razão moralmente legisladora" (Die Religion, AA VI, 62). A imagem originária (Urbild) que orienta a interpretação racional daquelas narrativas se encontra na própria razão, "devendo sempre ser buscada em nós mesmos" ou "em nenhum outro lugar a não ser em nossa razão" (Die Religion, AA VI, 63). Ora, ao deslocar o escopo da interpretação para o âmbito da sensificação das ideias da razão, portanto para a esfera da articulação do sentido, Kant dá o passo decisivo, do ponto de vista metodológico, para a constituição de uma nova hermenêutica que acabaria reivindicando em seu desenvolvimento histórico o status de procedimento metodológico fundamental da própria filosofia, como se vê em Heidegger. Em vez de tentar escamotear esta importância originária da contribuição kantiana, insistindo num suposto comprometimento de suas ideias com uma filosofia do sujeito que lhe é atribuída com base num mal-entendido muitas vezes proposital, caberia antes à história da hermenêutica moderna recuperar essa sua origem, sem dúvida das mais nobres. 